\section{Organização do espaço urbano e expansão do calazar}

\section{The organization of urban areas and expansion of kala-azar}

Eduarda Ângela Pessoa Cesse 1

Eduardo Freese de Carvalho 2

Paulo Paes Andrade 3

Walter Massa Ramalho 4

Luciano Luna 5

1 Departamento de Saúde Coletiva, Núcleo de Saúde Coletiva, Centro de Pesquisa Aggeu Magalhães, Fundação Oswaldo Cruz. Rua dos Coelhos, 450, $1^{\circ}$ andar, Coelhos, Recife, Pernambuco, Brasil. CEP: 50.070-550. e-mail: ecesse@elogica.com.br; educesse@cpqam.fiocruz.br

2 Departamento de Saúde Coletiva, Núcleo de Saúde Coletiva, Centro de Pesquisa Aggeu Magalhães, Fundação Oswaldo Cruz e Departamento de Medicina Social da Universidade Federal de Pernambuco

3,5 Departamento de Genética da Universidade Federal de Pernambuco

4 Centro Nacional de Epidemiologia

\section{Resumo}

Objetivos: verificar determinados processos que estão relacionados com a ocupação do espaço urbano e que contribuem para a ocorrência e expansão do calazar em um município de médio porte com acentuado fluxo migratório e em expansão econômica.

Métodos: trata-se de um estudo epidemiológico, de corte transversal, no qual se realizou a investigação domiciliar dos casos registrados em 8 bairros e respectivos setores censitários, no município de Petrolina, Pernambuco, no período de 1992 a 1997. Está subsidiado por elementos da pesquisa laboratorial, considerando o transmissor e o reservatório. Utilizamos o modelo explicativo da determinação social do processo saúde-doença a esta situação endêmica-epidêmica.

Resultados: observa-se uma concentração de casos de calazar na periferia da zona urbana do município de Petrolina, em áreas de invasão e expansão, onde o saneamento básico é precário, há a presença de animais e do vetor no peridomicílio e a população apresenta um baixo grau de instrução. O sexo masculino e a faixa etária de 0-4 anos são os mais acometidos.

Conclusões: os achados sugerem o estabelecimento de um novo padrão epidemiológico para o calazar em Petrolina, onde a ocorrência dessa endemia se dá em um espaço altamente modificado pela população. Tal situação caracteriza um processo de ruralização das áreas periurbanas endêmicas nas grandes cidades.

Palavras-chave Leishmaniose visceral, Doenças endêmicas, Epidemiologia 


\section{Introdução}

Com a crescente urbanização que ocorre em diferentes países após a II Guerra Mundial, amplia-se o interesse pela compreensão da relação entre urbanização e processos endêmicos. Ao longo das últimas décadas, verifica-se que a utilização de estratégias para controle e a erradicação de doenças, baseadas na teoria dos focos naturais das doenças transmissíveis, proposta na década de 30, torna-se insuficiente, na medida em que as doenças se incorporam ao espaço organizado pelo homem. Nesse sentido, os epidemiologistas buscam na Geografia Médica e nas Ciências Sociais, os modelos teóricos de explicação para o novo contexto epidemiológico verificado em todo o mundo. 1,2

Principalmente a partir da década de 80 , destacam-se alguns modelos explicativos da ocorrência dos fenômenos de saúde-doença que buscam contemplar a complexidade e a hierarquização dos diferentes níveis de seus determinantes. Nestes modelos as condições de vida se constituem num determinante explicativo fundamental, representando, para

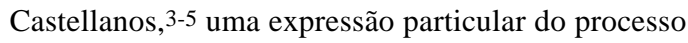
geral de reprodução da sociedade, onde os grupos populacionais apresentam um perfil de necessidades e riscos associados a tais condições.

Sabroza $^{6}$ e Paim ${ }^{7}$ consideram que a categoria espaço é um recurso potencialmente capaz de apreender processos relativos à reprodução social, na medida em que o conceito de território ou de espaço transcende a sua condição física ou natural e recupera o seu caráter histórico e social, sendo esta categoria suficientemente adequada para explicar a ocorrência e distribuição das endemias.

O espaço, considerado por Santos (1988: 26) ${ }^{8}$ como ".... um conjunto indissociável de que participam, de um lado, certo arranjo de objetos geográficos, objetos naturais e objetos sociais, e de outro, a vida que os preenche e os anima, ou seja a sociedade em movimento", incorpora os determinantes naturais e sociais numa visão de totalidade, que muitas vezes falta à análise epidemiológica. Desta forma, nós o empregamos, no sentido de buscar entender as relações sociais como definidoras do padrão social de uma cidade, decorrente do modo de produção econômica que se expressa em processos sociais de urbanização, de industrialização e de migrações internas.

Consideramos, ainda, que além do fenômeno da urbanização, considerado avassalador nos países do Terceiro Mundo, 8 o processo migratório, ultimamente associado ao próprio modelo de desenvolvimento econômico, altera a estrutura epidemiológica tanto das áreas de evasão, quanto das de recepção de migrantes, conduzindo a modificações dos perfis epidemiológicos das classes sociais ou frações destas classes, com reflexos imediatos sobre os riscos individuais da doença. ${ }^{9}$

Apoiados nestas considerações, destacamos a leishmaniose visceral ou calazar, agravo de ampla distribuição geográfica, que nas últimas décadas tem mostrado uma forte tendência à urbanização, com a ocorrência de surtos epidêmicos em várias capitais, se constituindo em um sério problema de saúde pública. ${ }^{10}$

O perfil epidemiológico do calazar se apresenta diferente do observado anos atrás, quando sua transmissão ocorria predominantemente na zona rural. Casas de barro e outras habitações precárias, ocupando de forma desorganizada o espaço situado no limite da cidade com a mata, com quintais onde se abrigam animais domésticos e de criação, favorecem o contato reservatório-vetor-homem e, por conseguinte, o surgimento de casos, contribuindo, portanto, para o aumento da incidência da doença.11-15

Destaca-se, no entanto, que a principal condição de transmissibilidade do calazar nesse novo ambiente está na adaptação do vetor, Lutzomyia longipalpis, ao peridomicílio, favorecida por fatores ainda não suficientemente estudados, e na presença de fontes de infecção ali introduzidas, sendo o cão doméstico considerado o principal reservatório da endemia, seguido do homem. 16 Neste sentido, partimos do entendimento de que a ocupação do espaço não ocorre ao acaso dos indivíduos, e sim tendendo a conformar conglomerados relativamente homogêneos do ponto de vista de suas condições de vida, onde a unidade espaço-população passa a ser uma unidade onde operam os processos determinantes das condições de vida e onde se expressam os problemas de saúde-doença, conforme destaca Castellanos. 5

A investigação da transmissão do calazar em áreas urbanas bem estabelecidas, é portanto, oportuno. Desde que no município de Petrolina, no estado de Pernambuco, vem se observando nos últimos anos a expansão do calazar, com um aumento preocupante do número de casos da doença na área urbana, ${ }^{17}$ consideramos fundamental realizar o presente trabalho com os seguintes objetivos: verificar a expansão do calazar, no município de Petrolina, Pernambuco, buscando identificar a presença de transmissão ativa em áreas urbanas e caracterizando os possíveis fatores determinantes deste processo, considerando os casos humanos, o reservatório e o transmissor. Em relação à população humana, estudar os casos autóctones da área urbana do município, considerando a distribuição temporal e espacial dos casos por bairro e setor censitário. Em relação ao trans- 
missor, verificar a existência de vetores em pontos de coleta selecionados, e, em relação ao reservatório, verificar a distribuição espacial dos cães com diagnóstico de calazar.

\section{Métodos}

Realizamos um estudo epidemiológico descritivo, de corte transversal, na área urbana do município de Petrolina, a partir da investigação domiciliar dos casos de calazar registrados no período de 1992 a 1997, onde consideramos um conjunto de informações relacionadas ao espaço de ocorrência da doença. O estudo é subsidiado, ainda, por elementos de pesquisa laboratorial, considerando o transmissor e o reservatório.

O município de Petrolina está localizado no Sertão pernambucano, mesoregião do São Francisco, e é caracterizado como de médio porte, estando o seu crescimento populacional relacionado a intensos processos migratórios.

O estudo de campo compreende os 8 bairros e respectivos setores censitários da zona urbana de Petrolina onde estão registrados 51 casos autóctones de calazar no período considerado no estudo os quais foram investigados através de questionário fechado, previamente elaborado.

Os bairros/setores censitários são carentes de infra-estrutura básica social (saneamento básico, calçamento de ruas, postos de saúde e creche). Possuem energia elétrica e água encanada, porém essa última não é fornecida com regularidade. Possuem, ainda, famílias vivendo em casa de taipa, papelão e lona plástica e os quais foram, na sua maioria, fundados na década de 80 e 90, com exceção de Vila Eduardo18 (Quadro 1).

Quadro 1

Perfil sócioeconômico e geográfico dos bairros e setores censitários onde se localizam os casos investigados de calazar humano na zona urbana de Petrolina, Pernambuco, 1992-1997.

\begin{tabular}{|c|c|c|c|c|c|}
\hline $\begin{array}{l}\text { Bairro Setor } \\
\text { Censitário }\end{array}$ & $\begin{array}{l}\text { Número de } \\
\text { casos } \\
\text { investigados }\end{array}$ & $\begin{array}{l}\text { Região de } \\
\text { localização dos } \\
\text { bairros }\end{array}$ & $\begin{array}{l}\text { Ano de } \\
\text { fundação do } \\
\text { bairro }\end{array}$ & $\begin{array}{l}\text { População do } \\
\text { bairro }\end{array}$ & Principais características dos bairros \\
\hline $\begin{array}{l}\text { São Gonçalo } \\
\text { 79sb,89sb,90sb,91sb } \\
\text { Cosme e Damião } \\
92 \\
\text { Dom Avelar } \\
86,88\end{array}$ & 21 & Norte & 1989 & 9.659 hab. & $\begin{array}{l}\text { Carentes de infra-estrutura básica social (sanea- } \\
\text { mento básico, calçamento de ruas, postos de } \\
\text { saúde, policiamento, posto telefônico e creche). } \\
\text { Possuem energia elétrica e água encanada, po- } \\
\text { rém esta última não é fornecida com regula- } \\
\text { ridade. Possuem famílias vivendo em casas de } \\
\text { taipa, papelão e lona plástica. }\end{array}$ \\
\hline $\begin{array}{l}\text { José e Maria } \\
76 \\
\text { João de Deus } \\
80,84,85\end{array}$ & 01 & $\begin{array}{l}\text { Norte } \\
\text { Norte }\end{array}$ & 1980 & $\begin{array}{l}15.660 \text { hab. } \\
11.113 \text { hab. }\end{array}$ & $\begin{array}{l}\text { Localizados na periferia da zona urbana com } \\
\text { exceção dos bairros José e Maria e Pedro Rai- } \\
\text { mundo que são próximos à região central do } \\
\text { município. }\end{array}$ \\
\hline $\begin{array}{l}\text { Pedro Raimundo } \\
63\end{array}$ & 02 & Norte & 1982 & 5.034 hab. & \\
\hline $\begin{array}{l}\text { Cohab São Francisco } \\
79 \mathrm{sb}\end{array}$ & 02 & Oeste & 1994 & 7.496 hab. & \\
\hline $\begin{array}{l}\text { Vila Eduardo } \\
37\end{array}$ & 01 & Leste & 1960 & 7.428 hab. & $\begin{array}{l}\text { Habitado há muitos anos. Possui uma comunidade } \\
\text { mista onde convivem pessoas de classe média e } \\
\text { pessoas de baixo poder aquisitivo. Bairro carente } \\
\text { de policiamento e com precário serviço de limpeza } \\
\text { pública. Saneamento básico não concluído. } \\
\text { Localizado próximo à região central do município. }\end{array}$ \\
\hline
\end{tabular}

hab. = habitantes 
Os critérios adotados para inclusão/definição de caso de calazar humano foram: residencia na área selecionada; ambos os sexos; todas as idades; diagnostico de portador de calazar no período de janeiro de 1992 a dezembro de 1997; registro em uma das fontes notificadoras consideradas no estudo. Pacientes identificados através de busca ativa, também foram incluídos.

Com o objetivo de complementar o diagnóstico dos casos humanos buscamos verificar a presença do vetor transmissor e do reservatório do calazar. Desta forma, realizamos sessões noturnas de coleta de flebótomos em três bairros, correspondentes a quatro setores censitários, utilizando capturadores manuais e armadilhas luminosas tipo CDC. Os flebótomos capturados foram identificados no laboratório de genética da Universidade Federal de Pernambuco. Os critérios utilizados para a definição dos bairros/setores censitários onde realizamos a coleta foram: a existência de registros de casos humanos, a proximidade da área com a caatinga, além de uma série de questões consideradas de risco, tais como a presença de animais no peridomicílio e de condições sócioeconômicas e sanitárias precárias.

No mesmo sentido, realizamos o estudo da positividade canina, a partir de dados secundários do Programa de Controle das Leishmanioses, Operações de
Controle do Reservatório Canino, Distrito de Salgueiro, da Fundação Nacional de Saúde (FUNASA), considerando a pesquisa sorológica, por imunofluorescência indireta, realizada no ano de 1997.

Digitalizamos os setores censitários a partir da malha do censo de 199120 e bairros da zona urbana de Petrolina, a partir de uma carta municipal de escala 1:10.000 e posteriormente lançamos as coordenadas em um software de geoprocessamento (MAPINFO), onde localizamos os casos humanos, os locais onde estão registrados cães com diagnóstico de calazar e os locais de coleta de flebótomos.

\section{Resultados}

A delimitação do Brasil, do Estado de Pernambuco e do município de Petrolina pode ser observada na Figura 1. Na Figura 2 observamos a distribuição dos casos investigados no perímetro urbano, no período de 1992 a 1997, onde a maior concentração ocorre na periferia dos bairros localizados no lado oeste. Destacamos que durante as investigações em campo podemos constatar a permanência de uma cobertura vegetal, do tipo caatinga, principalmente nas regiões mais periféricas do perímetro urbano, a qual denominamos "franja".

Figura 1

Localização de Petrolina em Pernambuco e no Brasil.

\section{- Petrolina}
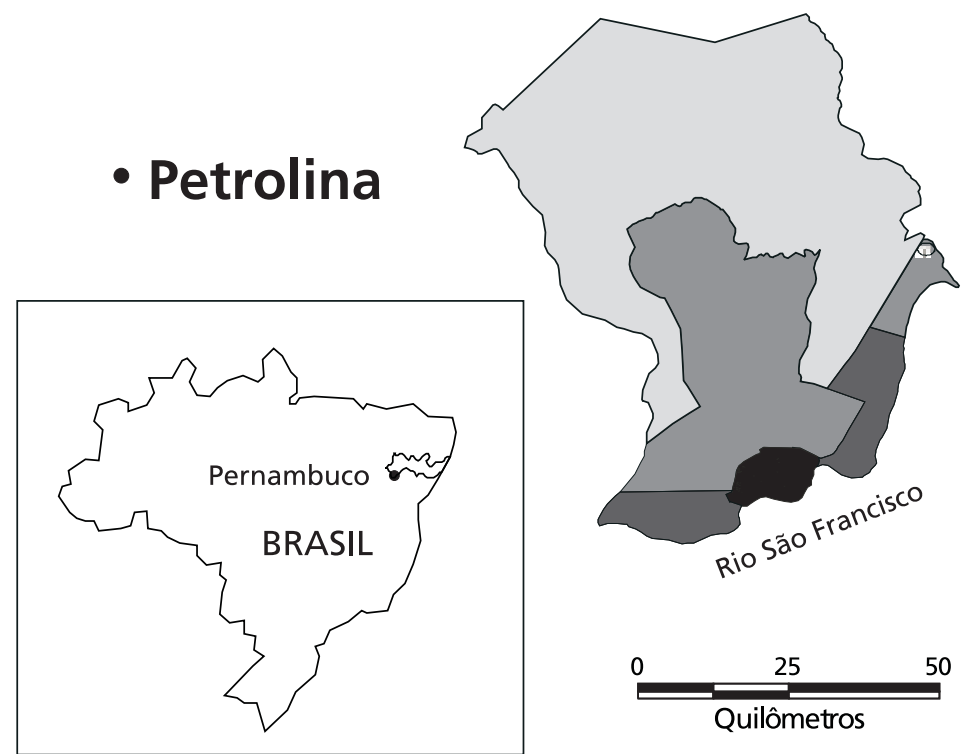

Área urbana

Sequeiro

Irrigado

Ribeirinha

Nota: no detalhe município de Petrolina 


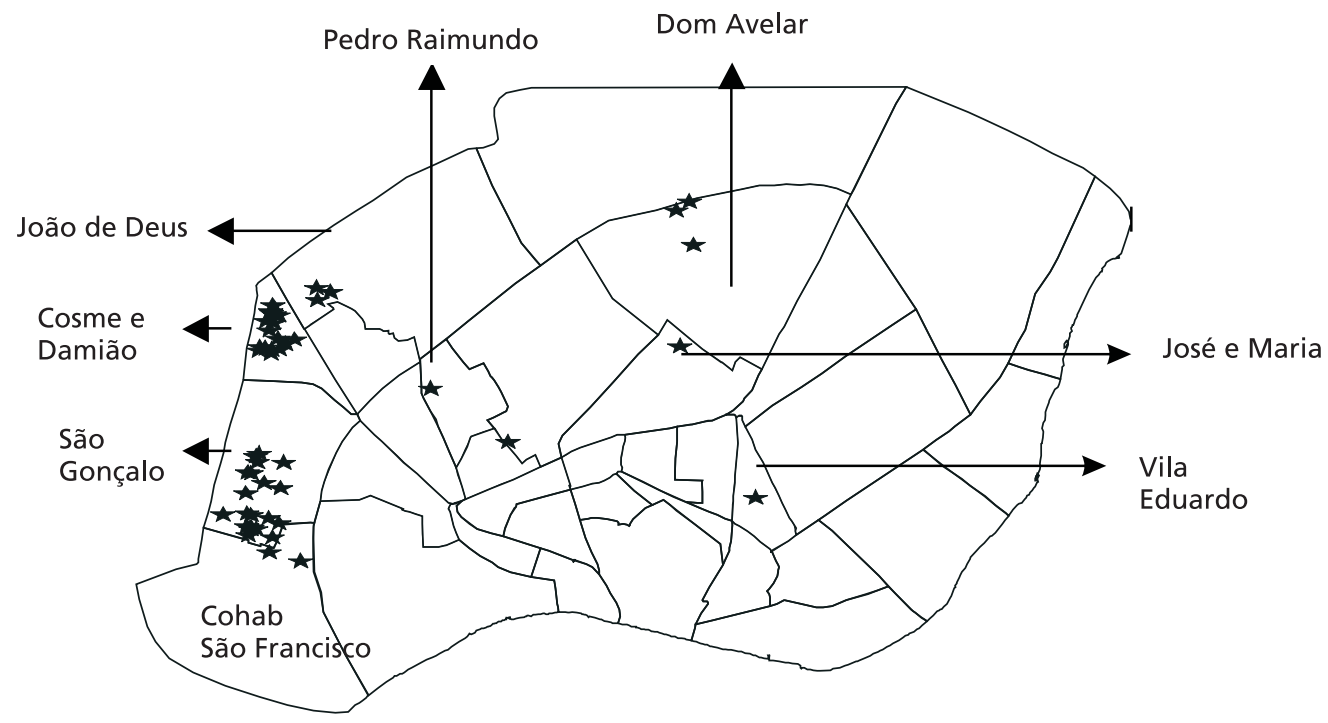

$\star \quad$ Casos humanos 1992 a 1997

A distribuição temporal (Figura 3) revela que os anos de 1992, 1993 e 1994 foram aqueles que apresentaram os menores registros de casos. Em 1995 observa-se uma importante elevação do número de casos, caracterizando um pico epidêmico. Nos anos seguintes do estudo, o número de casos regride e se mantêm constante.

Quanto à distribuição por sexo e faixa etária observamos que o maior percentual de casos ocorre no sexo masculino e na faixa etária de 0 a 4 anos (Figura 4).

Figura 3

Casos de calazar investigados por ano na zona urbana de Petrolina, Pernambuco, 1992-1997.

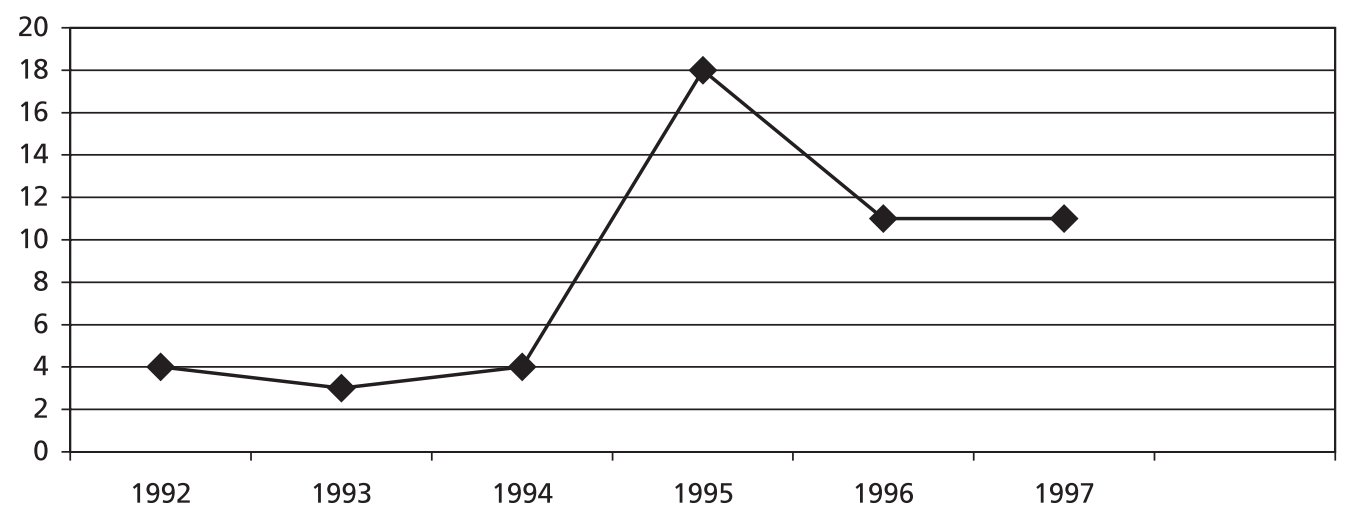


Casos investigados por sexo e faixa etária na zona urbana de Petrolina, Pernambuco, 1992-1997.

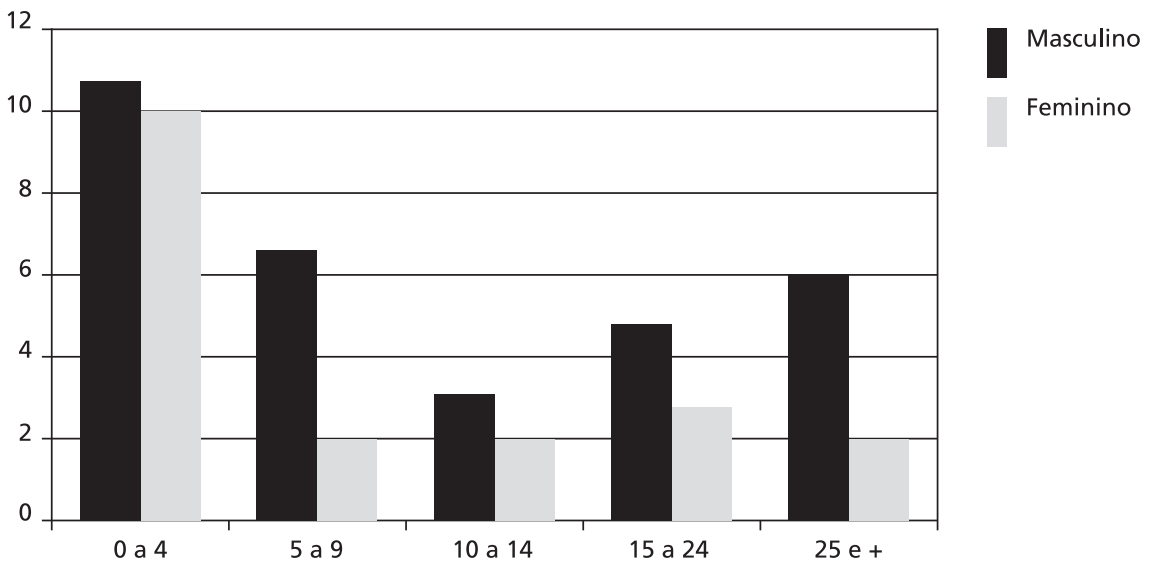

No que se refere às condições de moradia, observamos um conjunto de situações desfavoráveis, onde $16 \%$ das residências dos casos possuem menos de 2 cômodos, $12 \%$ não têm energia elétrica (mesmo em se tratando de área urbana), cerca de $30 \%$ das residências são de taipa, $8 \%$ apresentam cobertura de material diferente de telha cerâmica, 33\% apresentam piso de terra batida, $14 \%$ não possuem água encanada e $41 \%$ abrigam de 5 a 9 moradores.

Quanto à renda familiar, $47 \%$ dos casos entrevistados relatam que, na época em que adoeceram, tinham renda menor que o equivalente ao salário mínimo fixado em $\mathrm{R} \$ 120,00$ no ano de 1997 , e apenas $6 \%$ recebem mais de $\mathrm{R} \$ 500,00$. A escolaridade dos casos é precária, cerca de $70 \%$ estão no primeiro grau e outros $22 \%$ são analfabetos.

Observamos uma alta concentração de animais no domicílio e peridomicílio dos casos. Desta forma, cerca de $67 \%$ dos casos investigados relatam que possuíam animais em casa quando adoeceram, sendo freqüente a presença de cães e de animais de médio e grande porte.

Quanto à proximidade das residências com a mata, 76\% dos casos relatam este fato, demonstrando que os indivíduos acometidos, em sua maioria, moravam na periferia dos bairros, no limite com a caatinga, na época em que adoeceram.

No que se refere ao reservatório canino, encontramos registros de sorologias positivas para calazar, realizadas pelo Distrito de Salgueiro da FUNASA em grande parte dos bairros/setores censitários estudados. Procedemos a coleta de flebótomos, onde capturamos espécimes de Lutzomyia longipalpis nos bairros/setores censitários localizados no lado oeste e norte da área urbana do município. Este inseto foi encontrado em maior número no peridomicílio das residências em locais onde há a presença de animais. Estes achados podem ser observados na Figura 5. 
Áreas urbanas com a presença de sorologias caninas positivas identificadas pelo Distrito de Salgueiro, Coordenação Regional da FUNASA, em Petrolina, Pernambuco, 1997.

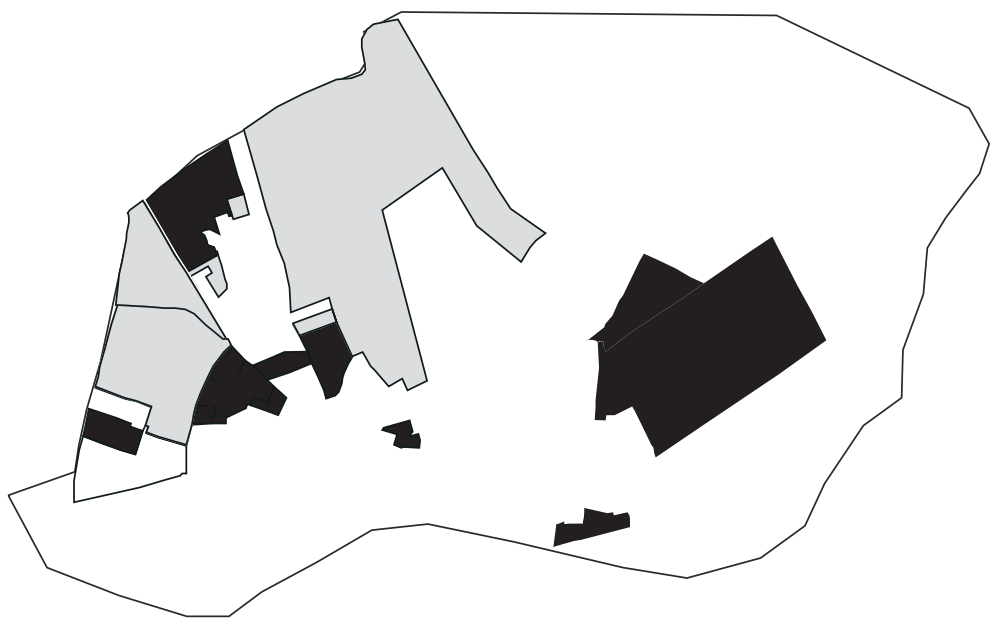

Setores com sorologia canina positiva

Setores com presença de flebótomos

\section{Discussão}

Petrolina vem se constituindo, nos últimos anos, em um importante pólo de exportação que tem como base a agricultura irrigada. ${ }^{21}$

Percebe-se, no município, um processo caracterizado pelo estabelecimento de um circuito espacial de produção, a exemplo do que assinala Santos, ${ }^{8}$ que é acompanhado de um crescimento populacional fruto da migração atraída pelas transformações advindas da irrigação. Porém, o incentivo ao processo de industrialização e a modernização da agricultura, desempregando o homem do campo e, paralelamente, expulsando-o para a cidade, foram responsáveis pelo crescimento desordenado do centro urbano, sem que estes tivessem correspondente oferta de empregos. Desta forma, uma parcela da população de Petrolina passa a ocupar áreas da cidade onde os investimentos em infra-estrutura não acompanham o crescimen- to verificado. Como conseqüência, verifica-se uma busca desenfreada de condições de sobrevivência que se traduz numa grande mobilidade interna.

Baseados nos estudos de Castellanos ${ }^{3-5}$ buscamos explicações para a ocorrência de doenças a partir dos níveis de determinação, onde as condições de vida são consideradas resultantes da forma como o grupo se insere no processo de reprodução da sociedade. Neste sentido, verificamos que as transformações e acumulações ocorridas no espaço territorial de Petrolina expressam as condições históricas de vida de seu povo. A cultura irrigada, o clima, a vegetação, o circuito econômico estabelecido nas últimas décadas revelam uma forma de organização social que evidencia as desigualdades entre o centro e a periferia. 21,22

É neste contexto que ocorre, no período de 1992 a 1997, um aumento do registro e da distribuição espacial do calazar em bairros urbanos de Petrolina, 
onde $76 \%$ dos casos de calazar investigados estão na periferia destes bairros, no limite com a mata local, denominada "franja". No ano de 1995 é verificada uma importante elevação no número de casos, o que sugere um pico epidêmico.

A periferia dos bairros se caracteriza por apresentar condições precárias de sobrevivência e situação ideal de transmissão de doenças. A precariedade verificada é apontada como condicionante para o estabelecimento do calazar: pobreza, desnutrição, grande número de cães infectados, oferta de fontes alimentares humanas e animais, arborização abundante em quintais, potenciais criadouros de insetos e acúmulos de lixo, presença de abrigos de animais silvestres no perímetro urbano, revelando que esta é uma doença de íntimas relações com as condições sociais às quais os indivíduos estão submetidos.12,16

Quanto à faixa etária, o padrão verificado corresponde àquele encontrado na literatura.13,14 Portanto, a faixa etária de 0 a 4 anos é a mais acometida, o que pode ser explicado pela condição de imunodepressão, causada pela desnutrição, geralmente observada na população dessa faixa etária, em áreas endêmicas. Quanto ao sexo, observa-se que a maior prevalência ocorre no masculino.

No que diz respeito às condições de moradia, a situação verificada é favorável ao estabelecimento do calazar, uma vez que são observadas residências bastante precárias.

Quanto ao reservatório animal que integra a cadeia de transmissão do calazar, evidenciamos a existência de uma grande quantidade de cães no domicílio e peridomicílio dos casos, além de outros animais que se constituem em fonte de alimentação para a fêmea do inseto vetor do calazar, o flebótomo. A captura de flebótomos em alguns bairros/setores censitários da área estudada mostra que, tanto nos bairros localizados no lado oeste da zona urbana de Petrolina, quanto naqueles localizados no lado norte, ocorre a presença da Lutzomyia longipalpis, espécie responsável pela transmissão do calazar. Os espécimes capturados estão localizados no peridomicílio de residências, geralmente próximos a animais domésticos e de criação. Para Marzochi e Marzochi 16 a principal condição de transmissibilidade do calazar em ambientes novos está na adaptação do vetor, Lutzomyia longipalpis, ao peridomicílio. O conhecimento da dinâmica do vetor é essencial para o adequado controle de sua população, uma vez que, sendo ele bem adaptável ao peridomicílio humano, o seu controle é muito importante para a interrupção da doença.

Este conjunto de fatos, aliado à migração e à forma de organização social do espaço urbano são ex- tremamente relevantes para a compreensão da expansão da endemia estudada em Petrolina, bem como para entender algumas das principais características da transmissão no município.

Por fim, no que se refere ao controle desta endemia, verificamos, durante os trabalhos de campo e a partir dos dados coletados, que as ações realizadas no Programa de Controle das Leishmanioses enfrentam atualmente dificuldades de ordem técnica e financeira, acarretando a não cobertura, por parte desta etapa do Programa de Controle, de todos os bairros que apresentam os critérios para a sua realização. 22

Desta forma, constatamos a ausência de um conjunto de ações necessárias para o enfrentamento da doença no município, como também o despreparo do sistema de saúde na resolução do processo de expansão da doença, uma vez que ignora como esta emergente endemia vem se incorporando ao espaço periurbano de Petrolina socialmente organizado pela população que nesta área se assenta. Esta última situação se encontra respaldada em estudos de Silva1,2 e Sabroza.23

\section{Considerações finais}

Os achados deste estudo sugerem o estabelecimento de um novo padrão epidemiológico para o calazar em Petrolina. Este novo padrão se caracteriza pela ocorrência e distribuição dessa endemia na periferia da zona urbana do município, no limite com a caatinga, que denominamos de "franja". Essa "franja" se apresenta como um espaço altamente modificado pela população que para ali se dirige e passa a conviver com um conjunto de fatores que condicionam o estabelecimento do calazar nestas áreas. Para Oliveira Filho e Melo, 24 tal situação caracteriza um processo de ruralização de áreas periurbanas endêmicas nas grandes cidades.

Reportando-nos ao modelo explicativo de Castellanos $3-5$ (Quadro 2), adaptado por Albuquerque25 às endemias de transmissão vetorial, verificamos que no nível do modo e processo de produção e reprodução social (geral), a estrutura econômica e política de Petrolina está baseada num desenvolvimento capitalista de produção, caracterizado pela exclusão e segregação de uma considerável parcela de sua população.

No que se refere ao nível da organização social do espaço urbano e produção de endemias (particular), verificamos que o grande fluxo migratório interno, a forma precária de organização da população nas áreas periurbanas do município, o baixo grau de 
instrução, a inserção na economia informal, a falta de saneamento, a presença de animais no peridomicílio, como também do vetor do calazar, aliados, possivelmente, à perda de capacidade operacional da FUNASA, responsável pelo controle no município, se traduzem na expansão do calazar.
Por fim, no nível onde ocorre o ciclo infeccioso básico (singular), verificamos o estabelecimento de um ciclo de transmissão ativa, com a presença de casos humanos, cães sorologicamente positivos e Lutzomyia longipalpis em pontos das áreas estudadas.

\section{Quadro 2}

Modelo para compreensão da transmissão do calazar urbano*

\section{Nível geral \\ Nível singular}

Modo do processo de produção e reprodução socia

$$
\downarrow
$$

Estrutura econômica e política baseada num desenvolvimento capitalista de produção, com exclusão e segregação da população e ausência de políticas públicas eficazes
Ciclo infeccioso básico

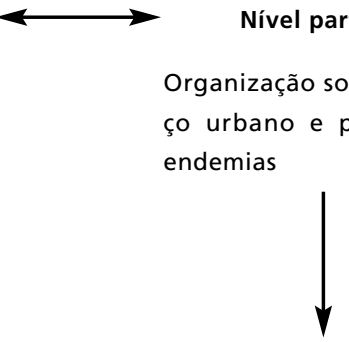

Ocupação desorganizada do espaço urbano/favelização com insuficiência de programas de habitação

Condições sanitárias precárias

Baixo grau de instrução

Predominância de casos no sexo masculino e na faixa-etária de 0 a 4 anos

Estratégias de sobrevivência popular com inserção na economia informal
Grupos de indivíduos infectados e doentes.

Alta densidade vetorial da Lutzomyia longipalpis na área periurbana.

Reservatório de cães sorologicamente positivos no peridomicílio.

* Baseado no modelo explicativo de Castellanos $3-5$ aplicado às endemias de transmissão vetorial. 


\section{Referências}

1. Silva LJ. Organização do espaço e doença. In: Textos de apoio: Epidemiologia 1. Rio de Janeiro: Associação Brasileira de Pós-Graduação em Saúde Coletiva (ABRASCO); 1990. p.159-85.

2. Silva LJ. O conceito de espaço na epidemiologia das doenças infecciosas. Cad Saúde Pública 1997; 13:585-93.

3. Castellanos PL. Sobre el concepto salud-enfermedad: un ponto de vista epidemiológico. Cuad Med Soc, 1987; 42 15-24.

4. Castellanos PL. Avances metológicos en epidemiologia. In: Anais do I Congresso Brasileiro de Epidemiologia; 1990 Set 2-6; Campinas, São Paulo. Rio de Janeiro: Associação Brasileira de Pós-Graduação em Saúde Coletiva (ABRASCO); 1990. p. 201-16.

5. Castellanos PL. Sistemas nacionales de vigilancia de la situação de la salud segun condiciones de vida y del impacto de las acciones de salud e bienestar. Washington, DC: Organização Panamericana da Saúde (OPAS); 1991. [mimeo].

6. Sabroza PC. Espaço e produção de endemias. In: 2 Taller da Associação Latino-Americana de Medicina Social; 1991; Caracas, 1991. [mimeo].

7. Paim JS. Abordagens teórico-conceituais em estudos de condições de vida e saúde: notas para reflexão e ação. In: Barata RB, organizadora. Condições de vida e situação de saúde. Rio de Janeiro: Associação Brasileira de PósGraduação em Saúde Coletiva (ABRASCO); 1997. p.730

8. Santos M. Metamorfose do espaço habitado: fundamentos teóricos e metodológicos da Geografia. São Paulo: HUCITEC; 1988.

9. Carvalheiro JR. Processo migratório e disseminação de doenças. In: Textos de apoio: Ciências Sociais 1. Rio de Janeiro: Associação Brasileira de Pós-Graduação em Saúde Coletiva (ABRASCO); 1986. p. 29-55

10. Waldman EA, Silva LJ, Monteiro CA. Trajetória das doenças infecciosas: da eliminação da poliomielite à reintrodução da cólera. In: Monteiro CA, organizador. Velhos e novos males da saúde no Brasil. São Paulo: HUCITEC; 1995. p.195-244

11. Leite G. Leichimaniose visceral: I parte: proêmio, histórico e epidemiologia. Rev Bras Med 1958; 15: 610-65.

12. Oliveira H. Epidemiologia do calazar. Rev Bras Med 1960; 17: 506-8.
13. Pessôa SB. Parasitologia médica. 7. ed. Rio de Janeiro: Guanabara Koogan; 1967. p.161-84.

14. Alencar JE, Neves J. Leishmaniose visceral (Calazar). In: Veronesi R. Doenças infecciosas e parasitárias. 7. ed. Rio de Janeiro: Guanabara Koogan; 1991. p.724-38.

15. Marzochi MC. Leishmanioses no Brasil: as leishmanioses tegumentares. JBM: J. Bras Med 1992; 63: (Curso): 82104.

16. Marzochi MC, Marzochi KBF. Leishmanioses em área urbana. Rev Soc Bras Med Soc 1997; 30 (Supl 1): 162-5.

17. Ministério da Saúde. Fundação Nacional de Saúde (FUNASA). Coordenação Regional. Relatório das atividades do programa de controle das leishmaniose. Recife: FUNASA; 1997. [mimeo].

18. Oliveira LMSR. Censo escola: situação da criança e do adolescente no município de Petrolina. Petrolina, Pernambuco: [s. n.]; 1995.

19. Petrolina (Pernambuco). Secretaria de Planejamento Estratégico. Censo 1996. Petrolina, Pernambuco: Secretaria de Planejamento Estratégico; 1997. [mimeo].

20. IBGE. Instituto Brasileiro de Geografia e Estatística. X Recenseamento geral brasileiro: censo demográfico 1991: resultados preliminares. Rio de Janeiro: IBGE; 1992.

21. Domingues RCA. Petrolina crescimento urbano e intervenção do Estado [dissertação mestrado]. Recife: Departamento de Ciências Geográficas da Universidade Federal de Pernambuco; 1989.

22. Cesse EAP. Expansão e urbanização da leishmaniose visceral: estudo epidemiológico do processo de transmissão ativa em área urbana - Petrolina, PE, 1992-1997 [dissertação mestrado]. Recife: Departamento de Saúde Coletiva, Centro de Pesquisas Aggeu Magalhães da Fundação Oswaldo Cruz; 1999.

23. Sabroza PC. Epidemiologia e a globalização: 4,2 bilhões de pessoas no planeta são consideradas 'mau negócio'. Tema 1998; (16): 4-5.

24. Oliveira Filho AM, Melo MT. The chemical control of vectors of leishmaniasis. Mem Inst Oswaldo Cruz 1994; 89 : 461-2.

25. Albuquerque MFPM. Urbanização, favelas e endemias: a produção e o controle da filariose bancroftiana no Recife [tese doutorado]. Rio de Janeiro: Escola Nacional de Saúde Pública da Fundação Oswaldo Cruz; 1995. 